\title{
Über das Blutdruckmessen, einen Selbstversuch und ärztliches Alltagshandeln
}

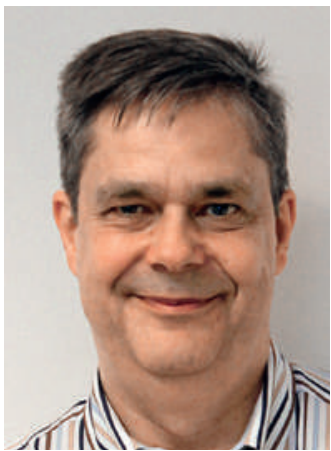

Eberhard Wolff
«So, jetzt nehme ich noch schnell Ihren Blutdruck.» Eine Routinepraxis in den Medizinalberufen, bei den Ärzten im Rahmen der «kleinen Untersuchung». Jeder Profi weiss: Das ist einfach und schnell gemacht, die Ergebnisse sind sofort da. Bei mir wurde nach einigen solcher Messungen in der letzten Zeit eine leichte Hypertonie diagnostiziert. Eine Routine im ärztlichen Alltagshandeln.

Jeder Profi weiss: Einzelmessungen beim Arzt sind wenig aussagekräftig. Sie liefern auch wegen der Aufregung in der Situation vielleicht verfälschte Werte. Ein gesundes Misstrauen gegenüber angezeigten Einzelwerten ist angebracht. Mein Hausarzt gab mir eines dieser 24-Stunden-Blutdruckmessgeräte mit. Die hinterher ausgespuckte Kurve liess das Bergpanorama der Churfirsten vor Neid erblassen. Jeder Profi weiss: Der Blutdruck ist ein extrem wechselhafter und von vielen Einflüssen abhängiger Wert. Aber wenn die Zahlen innerhalb einer Viertelstunde schnell einmal um 30 oder gar $40 \mathrm{mmHg}$ nach oben oder unten springen, obwohl ich diesen Tag ziemlich ruhig verlebt habe - kann sich da nicht auch ein Profi-Messgerät geirrt haben?

Mein hochgeschätzter Grundversorger meinte nach einem Blick auf die Kurve und den Durchschnitt trotzdem: erhöhter Blutdruck - mehr beobachten. Er empfahl mir ein Selbstmessgerät. Migros-Produkte seien gut genug, egal ob Handgelenk oder Oberarm. Blutdruckmessen ist ganz einfach. Wir hatten noch so ein Gerät zu Hause. Ein günstiges fürs Handgelenk. Es lieferte in den ersten Tagen viele bunte Werte an, und immer wieder auch in Ruhephasen solche, die ein Zombie im Computerspiel hat, kurz bevor er explodiert. Aber wieso? Schlechtes Gerät? Bin ich blöd und bediene es falsch? Ist mein Blutdruck am Ende, genauer: am falschen Ende? Blutdruckmessen ist doch einfach!

Zugegeben, hier habe ich mich dann bei einem Fehler überführt. Ich hätte das Gerät um 180 Grad zum Puls hin drehen müssen. Das müsste ein Selbstmess-Profi wissen. Zumindest die Zombie-Werte hörten jetzt auf.

Aber auch danach war ein systolischer Messsprung von 140 auf $180 \mathrm{mmHg}$ innerhalb einer Minute keine Seltenheit. Müssen wir uns den Blutdruck wie einen Ferrari beim Durchtreten des Gaspedals vorstellen? Ich habe dann irgendwann beschlossen, dass das Gerät nicht richtig misst. Das Internet bestätigte mich mit einem Testbericht. Blutdruckmessen sollte doch einfach sein.

Das neue Gerät ist mein ganzer Stolz. Es misst vom Oberarm direkt auf die Smartphone-App und wirft schicke Kurven aus. Die Werte wurden stabiler, sprangen aber immer noch. Ich fand heraus, dass bei der Sitzendmessung ein hoher Tisch und ein tiefer Stuhl schon einmal 20 Millimeter Messunterschied zu einem hohen Stuhl und einem tiefen Tisch ergeben können. Jeder Profi weiss: Immer in der gleichen Lage und mit dem Messgerät auf Herzhöhe messen. Blutdruckmessen ist ganz einfach - im Prinzip.

Mein Gerät misst mit seinen Pump- und Piepgeräuschen zum Leidwesen meiner Umgebung auf Wunsch dreimal direkt hintereinander. Die Hersteller wissen nämlich, dass Blutdruckmessen nicht ganz so einfach ist. Jetzt erkenne ich sofort, wenn die Werte bei gleichen Bedingungen immer noch hüpfen (was sie ab und zu gerne tun). Aber warum? Liegt es am Gerät, an meinem Messen oder an meinem Blutdruck? Meine Probleme möchte ich haben, sagte Tucholsky einmal.

Blutdruckmessen ist also doch nicht so einfach. Um Missverständnissen vorzubeugen: Es geht mir an dieser Stelle nicht um meinen Blutdruck. Der ist mein Privatproblem. Ich frage hier, wie die Profis es machen, dass es so einfach erscheint? Die sind doch nicht blöd. Klar, sie machen keine Anfängerfehler. Trotzdem: Wie gehen sie mit uneindeutigen Werten bzw. Befunden um? Glauben sie wirklich an die Wahrheit des einzelnen Messwerts? Ich vermute, dass der Unterschied zwischen einem beruflichen Blutdruckmesser und einem Patienten wie mir, der sich selbst misst, in etwas liegt wie der Fähigkeit, es in bestimmten Situationen nicht zu genau wissen zu wollen. Man darf im Berufsalltag auch nicht zu oft ins Grübeln kommen (am Ende zweifelt man noch an den offiziösen Grenzwerten, aber das ist ein anderes Thema).

Und gibt es im Gegenzug Techniken im professionellen ärztlichen Berufsalltag, um Unsicherheitsfaktoren bei Einzelbefunden (etwa auch bei Laborwerten) auszuschalten? Etwas, das mehr ist als der naheliegende Langzeit-Blick auf den Durchschnitt? Eine Mischung aus Erfahrung und Gefühl, die ihnen sagt, wann sie wie nachhaken müssen? Ich glaube, ich habe selber beim Blutdruckmessen bereits so etwas entwickelt und ahne, wann ich eine Messung wiederholen muss.

Wenn Sie mehr zu dieser Frage wissen wollen, lege ich Ihnen einen überaus interessanten Artikel von Marianne Jossen ans Herz, der in Ausgabe 13 dieses Blattes erscheint. Es geht darin um Entscheidungen und auch Intuition in der Medizin.

Mit solchen Techniken ist Blutdruckmessen dann wieder einfach(er). Das weiss eventell jeder Profi.

Eberhard Wolff * 